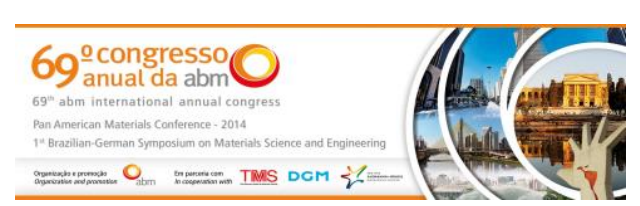

Theme: Environment management and waste recovery and treatment

\title{
THERMODYNAMIC STUDY OF EAFD GENESIS IN THE PRESENCE OF CHLORINE IN ELECTRIC ARC FURNACE*
}

Pedro Jorge Walburga Keglevich de Buzin ${ }^{1}$ Antonio Cezar Faria Vilela ${ }^{2}$ Nestor Cezar Heck ${ }^{3}$

\begin{abstract}
The steel production in mini mills generates several process residues, among them the electric arc furnace dust (EAFD). This residue has as main elements $\mathrm{Fe}, \mathrm{O}$, and $\mathrm{Zn}$, being classified as hazardous by the presence of $\mathrm{Pb}$ and $\mathrm{Cd}$. In recent years, a rise in the chlorine content of this residue was observed, motivated by the increased use of scrap with impurities bearing this element. In this work, a qualitative assessment of the presence of chlorine in the electric steelmaking process is made. Complementing it, theoretical considerations based on the computational thermodynamics tool FactSage show the effects of the chlorine on the mineral species in EAFD and on gaseous species in the gas phase $\left(\mathrm{HCl}\right.$ and $\left.\mathrm{Cl}_{2}\right)$. For this study, PVC polymer was used as the chlorine carrier substance which contaminates the EAF charge; presence of other minor elements in the system such as $\mathrm{K}, \mathrm{Na}$ and $\mathrm{Pb}$ were also considered.
\end{abstract}

Keywords: EAFD; Chlorine; Computational thermodynamics.

1 Chemical Eng., MSc., Laboratório de estudos ambientais, LEAmet, UFRGS, Porto Alegre, RS, Brazil.

2 Metal. Eng., Dr., Laboratório de siderurgia, LASID, PPG3M, UFRGS, Porto Alegre, RS, Brazil.

3 Metal. Eng., Dr., Núcleo de Term. Comput. para a Metalurgia, NTCm, PPG3M, UFRGS, Porto Alegre, RS, Brazil.

* Technical contribution to the $69^{\text {th }} A B M$ International Annual Congress and to the ENEMET, July $21^{\text {st }}-25^{\text {th }}$, 2014, São Paulo, SP, Brazil. 


\section{INTRODUCTION}

\subsection{EAFD Birth and the Fe-O-Zn System}

The technological alternative used in steelmaking by most semi-integrated plants or mini-mills is the electric steel melting shop, which employs the electric arc furnace, $\mathrm{EAF}$, as scrap melting equipment, and the ladle furnace, LF, as refining equipment. During melting and refining of the charge, generation of electric arc furnace dust, EAFD, occurs at a ratio ranging between 1 and 2 wt.\% of the steel plant production. According to Guézennec et al. [1], the main dust forming mechanisms are: volatilization (27 wt.\% of the EAFD) and bursting of carbon monoxide (CO) bubbles (60 wt.\% of the EAFD). The direct fly-off of solid particles (dragging of slag and other charge materials) takes place, but is limited - provided that sufficient operating caution is taken. The residue (fine particles) must be removed from the furnace (together with gases from the melting and refining of the load) in order to leave a healthy environment for the steelmaking plant workers.

Concerning EAFD minerals, they may be important regarding co-processing and recycling. EAFD minerals are the end result of a series of phenomena occurring in the oven (type and amount of scrap, added materials, formation mechanisms and specific parameters of each plant or furnace like temperature, oxygen partial pressure, etc.) plus the successive physicochemical equilibria by which gases and dust must cross during its trajectory from oven to the dust dock (including postcombustion and cooling stages).

In view of the fact that EAFD stems mainly from the metal bath (vaporization and bubble bursting), disregarding momentarily the dragging of solid particles, it is understandable that this waste is largely composed of oxides of iron: $\mathrm{Fe}_{2} \mathrm{O}_{3}$ and $\mathrm{Fe}_{3} \mathrm{O}_{4}$.

EAFD composition also reflects scrap composition and other input materials present in the charge. Once steel durability can be prolonged by $\mathrm{Zn}$ coating, the increased use of galvanized steel parts is resulting in a large galvanized scrap amount arriving at the steelmaking plant. Consequently, $\mathrm{Zn}$ is now the major element in EAFD next to iron and oxygen. Accordingly, major mineral species found in the dust are becoming the solid oxides of iron and zinc: hematite, magnetite, zincite $(\mathrm{ZnO})$ and franklinite $\left(\mathrm{ZnFe}_{2} \mathrm{O}_{4}\right)$ [2].

\subsection{Chlorine in Electric Arc Furnace Melting Shops}

Other elements may also be present in varying amounts in EAFD; in recent years, an increase in chlorine content, motivated by the increased use of scrap containing this element as impurity, has been observed. Often chlorine becomes the fourth most abundant element in EAFD after iron, oxygen and zinc. Average contents of about $5 \%$ by weight of chlorine in the dust have been reported [3]. Accordingly, depending on the abundance, chlorine can disturb the mineral species formation, enabling the creation of new solid phases and gaseous species, interfering deeply in the reuse and the treatment of this waste, by both pyrometallurgical as well as hydrometallurgical ways [4].

Main source of element chlorine may be placed in materials of organic nature, such as polymers, paints, oils, rubber, etc.; but also inorganic materials (mineral species) accompanying the scrap such as: $\mathrm{NaCl}$ and $\mathrm{KCl}$ can be seen as (minor) sources. Contamination of scrap by organic compounds is largely due to the presence of

\footnotetext{
* Technical contribution to the $69^{\text {th }}$ ABM International Annual Congress and to the ENEMET, July $21^{\text {st }}-25^{\text {th }}, 2014$, São Paulo, SP, Brazil.
} 


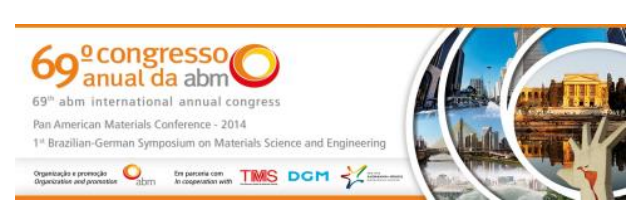

obsolete scrap originating from end-of-life goods [5]; as pointed out by Nakayama \& Kubo [6], in spite of the constantly changing nature of the scrap composition, it contains up to $2 \%$ of such contaminants.

Concerning organic materials, the furnace charging method can be of awareness when dealing with flue gases and particulate matter. In discontinuous loading systems (used by most of electric melt shops in operation), the electric arc furnace is a batch processing operation at temperatures up to about $1650^{\circ} \mathrm{C}$. Process includes (with repetition of some steps): opening the oven, loading of raw materials, closing the oven, melting (some refining operation may take place) and pouring in a cycle of about an hour of duration [6]. Conversely, in continuous systems (such as Consteel) scrap is continuously fed into the EAF, being brought by a horizontal transporter passing through a channel-like preheating section. In this section, the passage of the exhaust gases from the EAF at temperatures around $900^{\circ} \mathrm{C}$ results in the preheating of the scrap load to about 300 to $400^{\circ} \mathrm{C}$ [7].

In the batch system during the loading step of the EAF through large buckets (baskets) carried by bridge crane, it is common to observe the formation of flames and fumes when the scrap load reaches the furnace bottom. According to Birat et al. [5], immediately after the unloading of each bucket, a peak of volatile organic compounds, VOC, can be recorded with the measuring equipment.

These emissions result from the pyrolysis of organic compounds adhered to scrap when it undergoes an abrupt heating in contact with the walls and the hot materials present inside the EAF. The compounds formed by pyrolysis, in sequence, combust with the surrounding air forming exhaust flue gases. Particulate matter is also created during this step [6] and the possible formation of simple compounds of chlorine as hydrochloric acid cannot be ruled out. This off-gas stream, called secondary emission, is collected by the canopy hood and routed to the EAF/LF dedusting system.

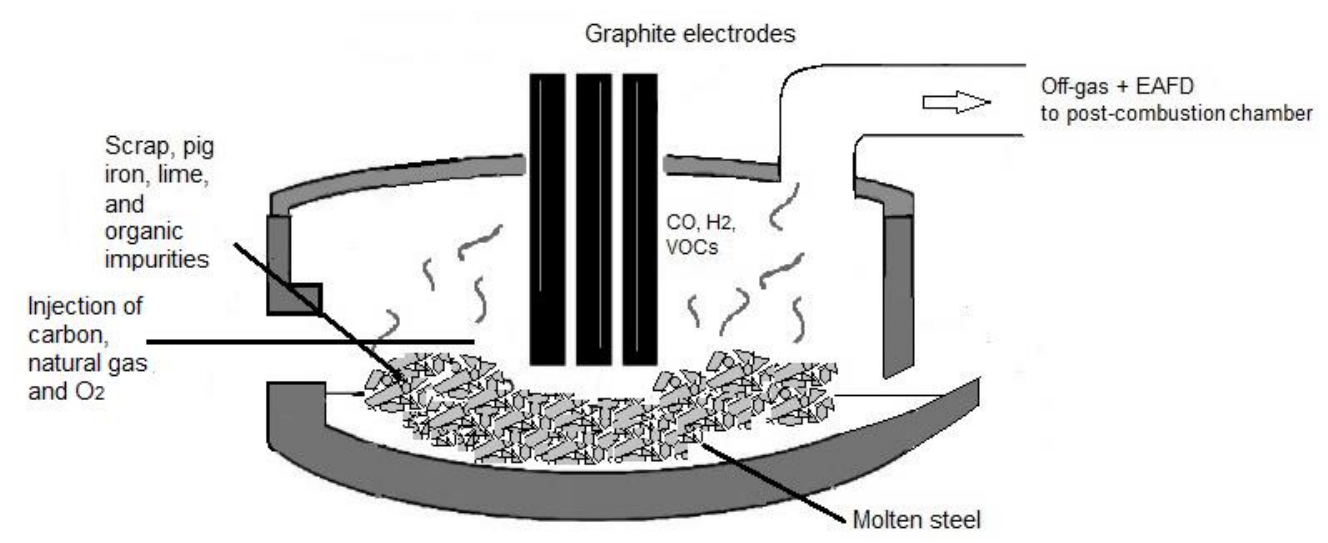

Figure 1. Main features of the EAF and local conditions which lead to the formation of the gaseous species and solid phases (minerals) contained respectively in gaseous emissions and EAFD.

The melting of the scrap starts after the closing of the EAF dome roof and the reintroduction of the graphite electrodes. At this stage temperature increases and zinc (together with iron) volatilizes from the scrap and bath. During this step, together with EAFD, off-gas is also generated due to the use of carbon-containing raw materials (pig iron), fuel (natural gas) and oxygen. The pyrolysis of the remaining organic compounds occurs simultaneously with scrap melting, generating VOCs and other compounds. Consequently, the conditions for the occurrence of reactions

\footnotetext{
* Technical contribution to the $69^{\text {th }}$ ABM International Annual Congress and to the ENEMET, July $21^{\text {st }}-25^{\text {th }}$, 2014, São Paulo, SP, Brazil.
} 
between all existing elements in the load are well set up, Figure 1.

The pyrolysis of organic compounds containing chlorine (both during loading and melting of the charge) leads to simpler gas compounds, especially hydrochloric acid [8].

The post-combustion of the exhaust gases is a critical part of the EAF dedusting system, and is brought about in order to burn $\mathrm{CO}$ and $\mathrm{H}_{2}$ into $\mathrm{CO}_{2}$ and $\mathrm{H}_{2} \mathrm{O}$ (to avoid hazardous explosions inside the dry section ducts of the exhaust system) and simultaneously to destroy the remaining organic compounds [5]. This operation is undertaken in a chamber located next and after the 'fourth hole', and gases leaving this chamber have a temperature close to $1000{ }^{\circ} \mathrm{C}$. The hot gas is cooled down to approximately $350^{\circ} \mathrm{C}$ through a water jacketed duct and then mixed with the gas flow coming from the remaining part of the exhaust system (e.g., hood and LF furnace).

Measurements of hydrochloric gas $(\mathrm{HCl})$ level in the water-cooled duct showed a very high concentration (close to $1000 \mathrm{ppm}$ ) during the early stage of the melting period [6]; this fact can lead to the incidence of corrosion phenomena in steel parts of the exhaust system.

At the end of the exhaust system, particulate matter generated during the scrap melting and steel refining operation is retained in filter bags (becoming the EAFD) while the gas phase (fumes resulting from combustion and post-combustion processes) crosses and is delivered to the atmosphere.

\subsection{Potassium, Sodium and Lead in Electric Arc Furnace Melting Shops}

Beside $\mathrm{Cl}, \mathrm{C}$ and $\mathrm{H}$, other inorganic elements are usually present in minor amounts in the EAFD. In order of importance, the following three elements can be cited: potassium, sodium and lead.

The interaction between these elements leads to new gaseous and solid species in the exhaust flue gas and EAFD. Solid chloride compounds are of importance only at the lower end of the temperature scale.

Certainly, reaction kinetics is of paramount importance in the speciation of the condensed phases at temperatures below $600{ }^{\circ} \mathrm{C}$, nevertheless this is outside the reach of the thermodynamic tool used in the present work.

\subsection{Setting Work Bounds and Objectives}

The analysis of the several physicochemical conditions and the corresponding mineral species (and thermodynamic phases) constituents of EAFD stemming from the three main elements of the dust, namely: iron, zinc and oxygen, were undertaken in previous works $[9,10]$ and will be only repeated here.

In the present work, new thermodynamic determinations, including the elements chlorine, hydrogen and carbon (originating from the pyrolysis and combustion of organic matter), will be made.

As an important remark, one should distinguish this work from others [8,9], which aim to study the possibility of recovering metals from PAE using chlorine - these processes must be classified (chemically) among the chloridizing roasting processes. Besides, the formation of dioxins and other chlorinated organic compounds will not be considered here.

Main objective of this work is consequently to study the role and influence of chlorine, hydrogen and carbon (followed by sodium, potassium and lead) in the formation of the gaseous and mineral species present in exhaust gases and EAFD.

\footnotetext{
* Technical contribution to the $69^{\text {th }} A B M$ International Annual Congress and to the ENEMET, July $21^{\text {st }}-25^{\text {th }}$, 2014, São Paulo, SP, Brazil.
} 


\section{METHODOLOGY}

\subsection{Software and Databases}

The thermodynamic equilibrium states (for every system under study in the present work) were determined using the Equilib module of FactSage software (version 6.4) software is described elsewhere by Bale et al. [11].

The following databases were employed:

- FSstel - FactSage steel intermetallic compounds and alloy solutions;

- FToxid - FACT oxide compounds and solutions database;

- FactPS - FactSage compound database.

\subsection{Simulation Conditions}

In the study of the EAFD-birth in the presence of the element chlorine (plus $\mathrm{H}$ and $\mathrm{C}$ ) by means of computational thermodynamics, a hypothetical EAFD base composition was considered, as indicated in Table 1:

Table 1. EAFD hypothetical base composition

\begin{tabular}{|c|c|c|c|c|c|}
\hline Element & $\mathrm{Fe}$ & $\mathrm{Zn}$ & $\mathrm{O}$ & $\mathrm{Cl}$ & Other \\
\hline Wt.\% & 44 & 11 & 21 & 5 & 19 \\
\hline
\end{tabular}

The amount of chlorine effectively used as input was obtained by trial and error, adding an initial input amount of $\mathrm{Cl}$ and, next, controlling the outcome of the final composition in EAFD - since part of the chlorine is carried by the gaseous emissions. Chlorine was added to the system closely linked to carbon and hydrogen amounts, reflecting its (suggested) organic origin. The mole ratio of $\mathrm{C}, \mathrm{H}$ and $\mathrm{Cl}$ found in the compound Polyvinyl Chloride $\left(\mathrm{C}_{2} \mathrm{H}_{3} \mathrm{Cl}\right), \mathrm{PVC}$, was chosen here, so that as result three moles of hydrogen and two moles of carbon are introduced into the system per mole of chlorine added.

Reflecting what succeeds in post-combustion system, (excess) air is added to the system until the nitrogen content in the exhaust gas stream shows a partial pressure close to that of air ( $78 \mathrm{vol} . \% \mathrm{~N}_{2}$ in gaseous emissions).

Incoming air had a relative humidity value of $60 \%$ at $25{ }^{\circ} \mathrm{C}$, reflecting a value common to many places in the world (but no water was admitted coming from the electrode cooling system).

The weight fraction of $\mathrm{Fe}$ with respect to iron plus zinc in the system $(\mathrm{Fe} /(\mathrm{Fe}+\mathrm{Zn}))$ was selected and maintained in $80 \%$, i.e., according to previous publications, it means that the EAFD can be seen as mixture of the minerals franklinite and hematite.

Other elements in the system are inert, not interfering in chemical reactions with the main elements. Their input mass is such that composition reaches the desired base composition displayed in Table 1.

For the analysis of the influence of $\mathrm{K}, \mathrm{Na}$ and $\mathrm{Pb}$, an equal input mass amount of each element was added to the system. This correspond to a value of around 0.5 wt. $\%$ of any of these elements computed on the total mass of the condensed phases.

* Technical contribution to the $69^{\text {th }} A B M$ International Annual Congress and to the ENEMET, July $21^{\text {st }}-25^{\text {th }}$, 2014, São Paulo, SP, Brazil. 


\section{RESULTS AND DISCUSSION}

The present thermodynamic analysis was made considering only nine elements on the genesis of EAFD and the corresponding gas phase, namely: $\mathrm{Fe}, \mathrm{O}, \mathrm{Zn}, \mathrm{Cl}, \mathrm{H}, \mathrm{C}$, $\mathrm{Na}, \mathrm{K}$ and $\mathrm{Pb}$. Any analysis considering few elements, i.e. which takes into consideration a system that is far simpler than a real one - like the intricate situation existing inside an EAF and exhaust ancillary system -, is subject to error. Yet, simplicity is frequently essential for clarity and the understanding of complex problems. Last but not least, knowledge of the phase relations in lower order systems (binary and ternary) is crucial for a better understanding of higher order systems (quaternary, quinary etc.).

\subsection{Analysis of Condensed Phases}

Initially, in order to provide a reference, the phases (and the proportions between them) in the system at equilibrium, computed using the simplest Fe-Zn-O system (i.e. without the presence of elements $\mathrm{Cl}, \mathrm{H}, \mathrm{C}, \mathrm{Na}, \mathrm{K}$ and $\mathrm{Pb}$ ) as a function of the temperature, are presented in Figure 2.

The results show that for the composition chosen, at a temperature of $1600{ }^{\circ} \mathrm{C}$, among the various condensed phases that could participate in the equilibrium state, there is in fact only spinel. Decreasing the temperature, this phase increases its mass slightly; then, in the temperature range between 1250 and $700{ }^{\circ} \mathrm{C}$, there is a steep decrease. At $1250{ }^{\circ} \mathrm{C}$ hematite phase also appears in the system. The hematite, on the contrary, shows the opposite behavior, increasing its mass in the same direction of the decreasing temperature. The masses of the two phases finally stabilize and the ratio between them shows a fixed value between 700 and $100{ }^{\circ} \mathrm{C}$.

Therefore, at the end of the cooling stage, there are no other phases in the system behind gas, hematite and spinel phases.

The following Figures 3, 4 and 5 show the condensed phases present in equilibrium, when $\mathrm{Cl}, \mathrm{H}, \mathrm{C}, \mathrm{Na}, \mathrm{K}$ and $\mathrm{Pb}$ are added into the system.

As it can be seen, the relative amount of phases hematite and franklinite varies, as the temperature reaches the lower end of the scale, with the formation of several chloride condensed phases.

In a few words, this means that chlorine in the gas phase 'extracts' zinc from franklinite (spinel) in a greater or lesser extent, transforming it into hematite.

No great changes are to be seen at the higher end of the temperature scale concerning the condensed phases.

Zinc chloride loses importance and gives way to the formation of other chlorides of $\mathrm{Na}$ and $\mathrm{K}$. But also a lead chloride phase is to be seen participating of the equilibrium state when $\mathrm{Pb}$ is present in the system, Figures 6 and 7 .

There would be enough energy in the system to overcome the activation energy barrier that would trigger these transformations at the lower end of the temperature scale? The answer to this question is difficult to be given only by thermodynamics. One can, however, speculate that if this does not occur, then the level of the species at an intermediate temperature will probably not change, and their relative amounts will remain constant up to the room temperature.

In any case, taking into consideration the data from EAFD chemical analysis, it is known that there are chlorine-containing phases in it.

\footnotetext{
* Technical contribution to the $69^{\text {th }}$ ABM International Annual Congress and to the ENEMET, July $21^{\text {st }}-25^{\text {th }}$, 2014, São Paulo, SP, Brazil.
} 


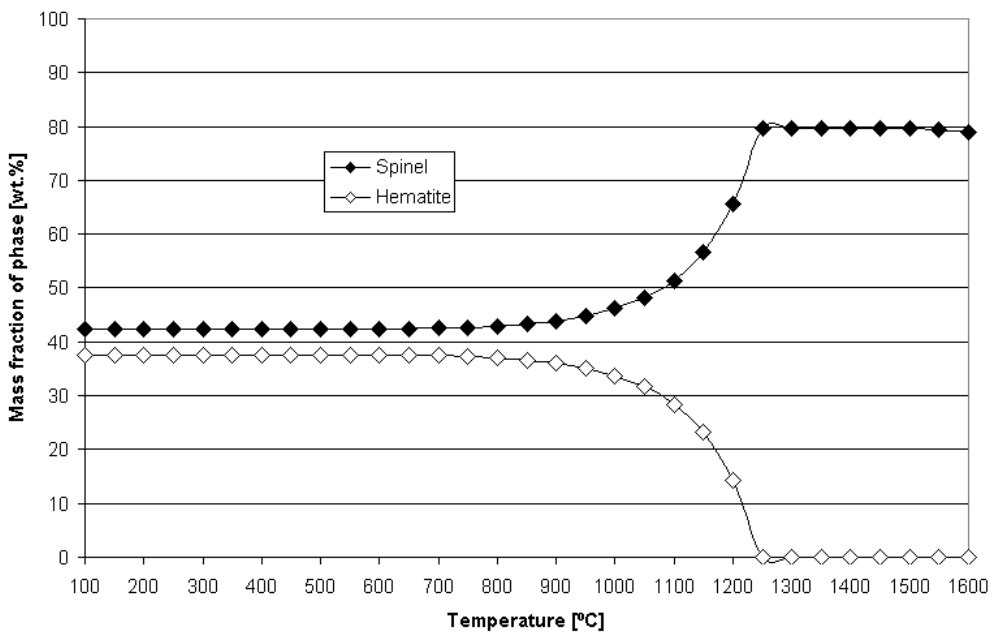

Figure 2. Condensed phase amount as a function of the temperature; Fe-Zn-O system.

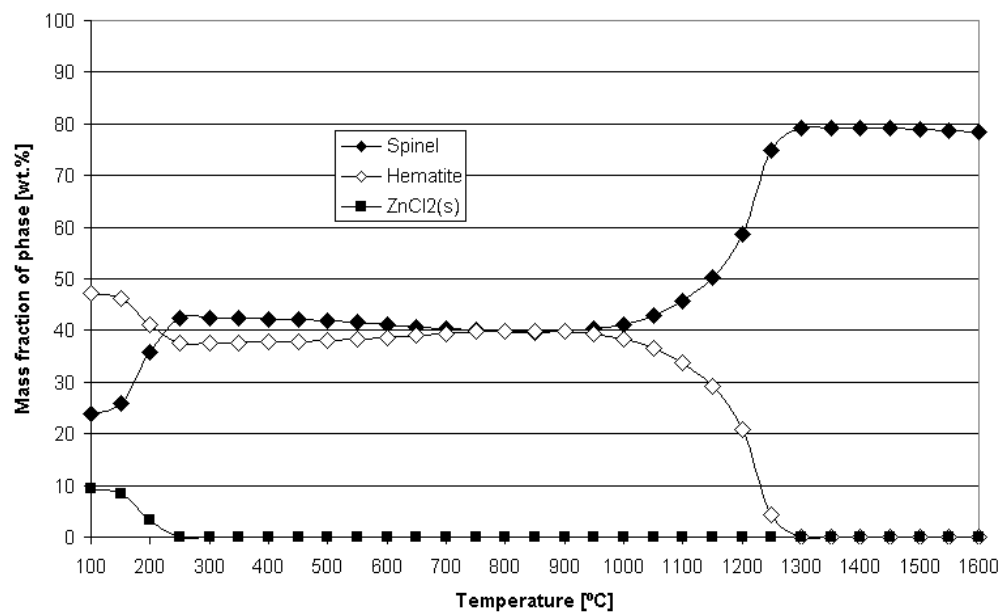

Figure 3. Condensed phase amount as a function of the temperature; $\mathrm{Fe}-\mathrm{Zn}-\mathrm{O}-\mathrm{Cl}-\mathrm{H}-\mathrm{C}$ system.

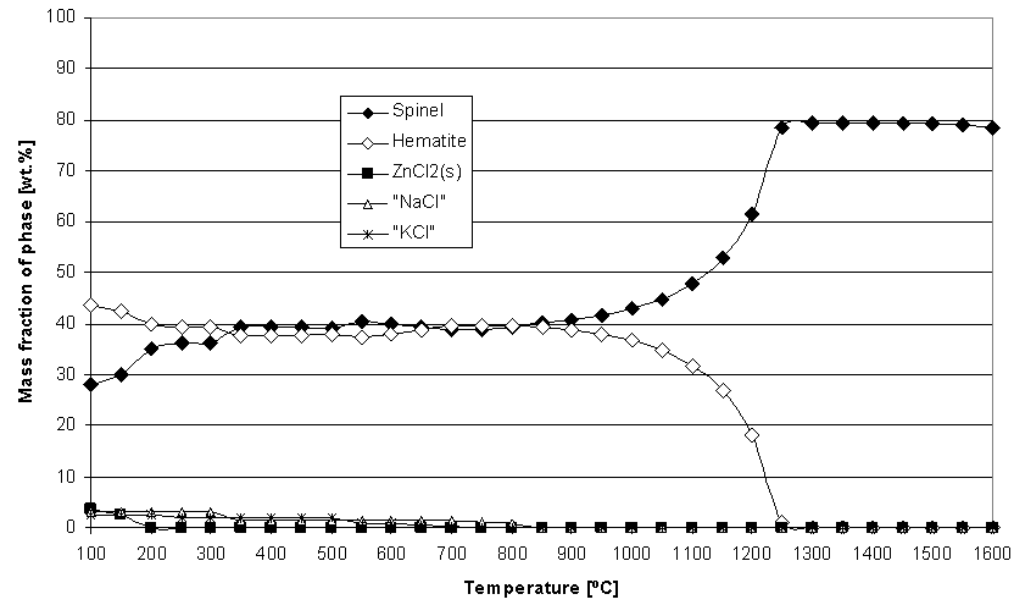

Figure 4. Condensed phase amount as a function of the temperature; $\mathrm{Fe}-\mathrm{Zn}-\mathrm{O}-\mathrm{Cl}-\mathrm{H}-\mathrm{C}-\mathrm{Na}-\mathrm{K}$ system.

* Technical contribution to the 69th ABM International Annual Congress and to the ENEMET, July $21^{\text {st }}-25^{\text {th }}, 2014$, São Paulo, SP, Brazil. 


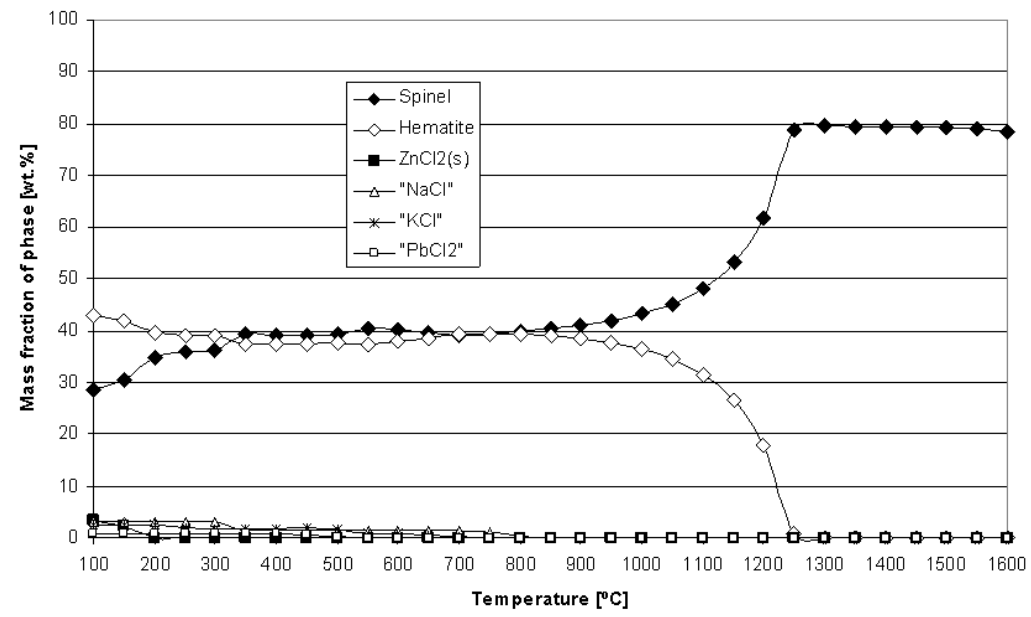

Figure 5. Condensed phase amount as a function of the temp.; Fe-Zn-O-Cl-H-C-Na-K-Pb system.

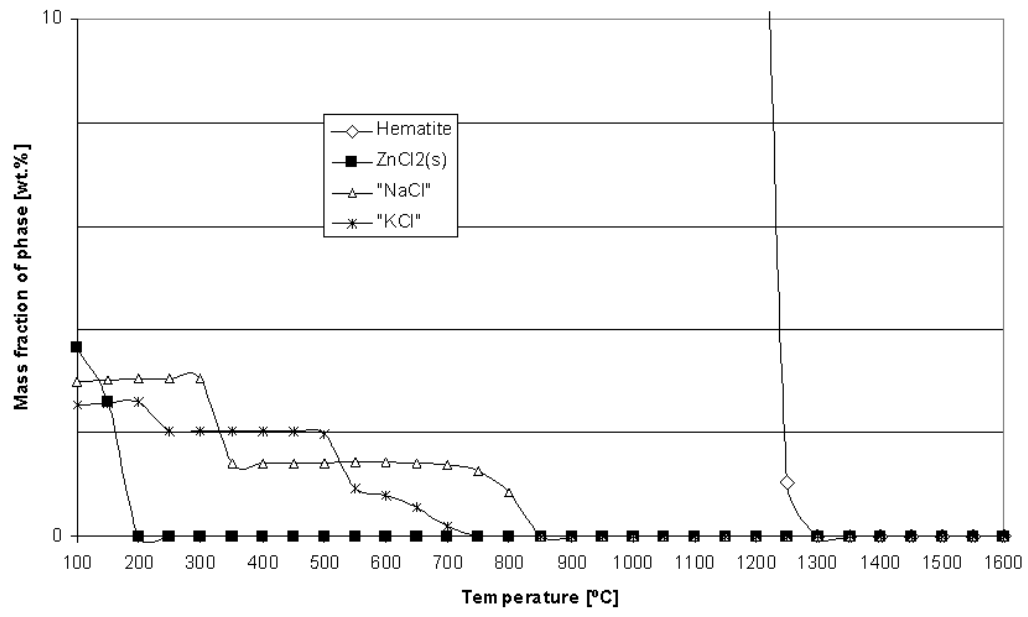

Figure 6. Lower mass section; Fe-Zn-O-Cl-H-C-Na-K system.

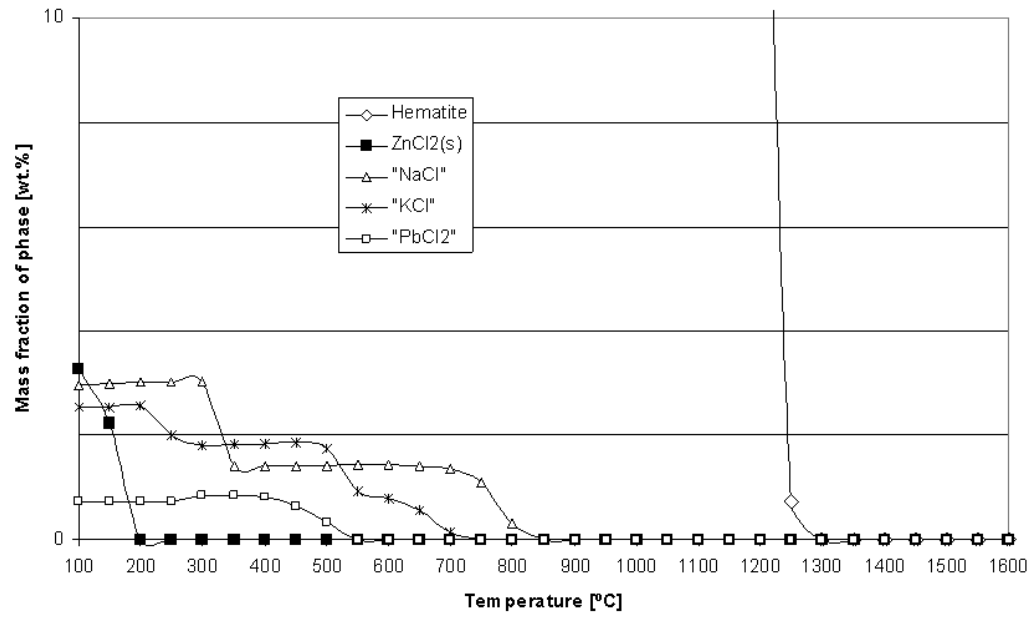

Figure 7. Lower mass section; Fe-Zn-O-Cl-H-C-Na-K-Pb system.

* Technical contribution to the 69th ABM International Annual Congress and to the ENEMET, July $21^{\text {st }}-25^{\text {th }}$, 2014, São Paulo, SP, Brazil. 


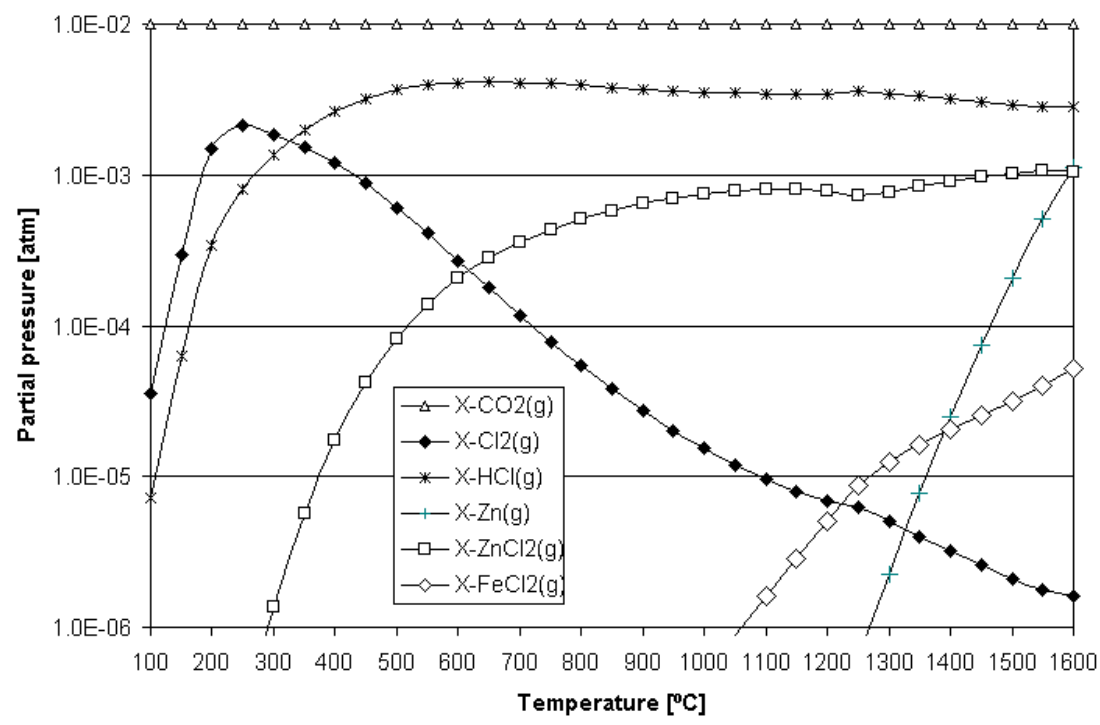

Figure 8. Gas phase constituents; system Fe-Zn-O-Cl-H-C.

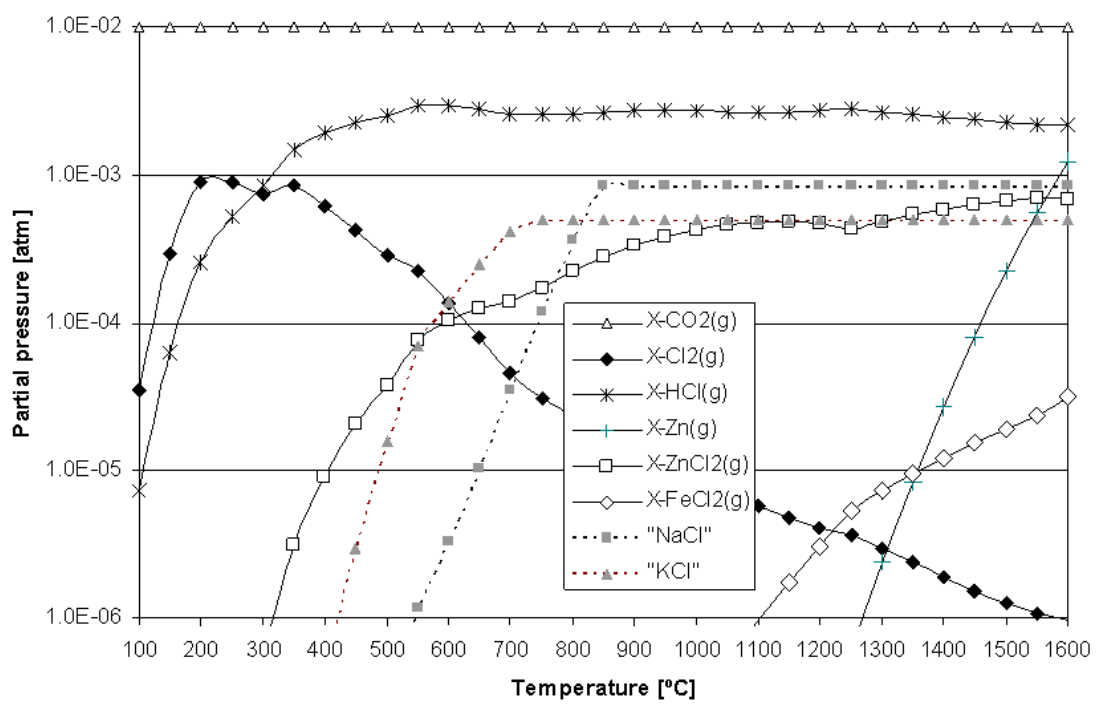

Figure 9. Gas phase constituents; system Fe-Zn-O-Cl-H-C-Na-K.

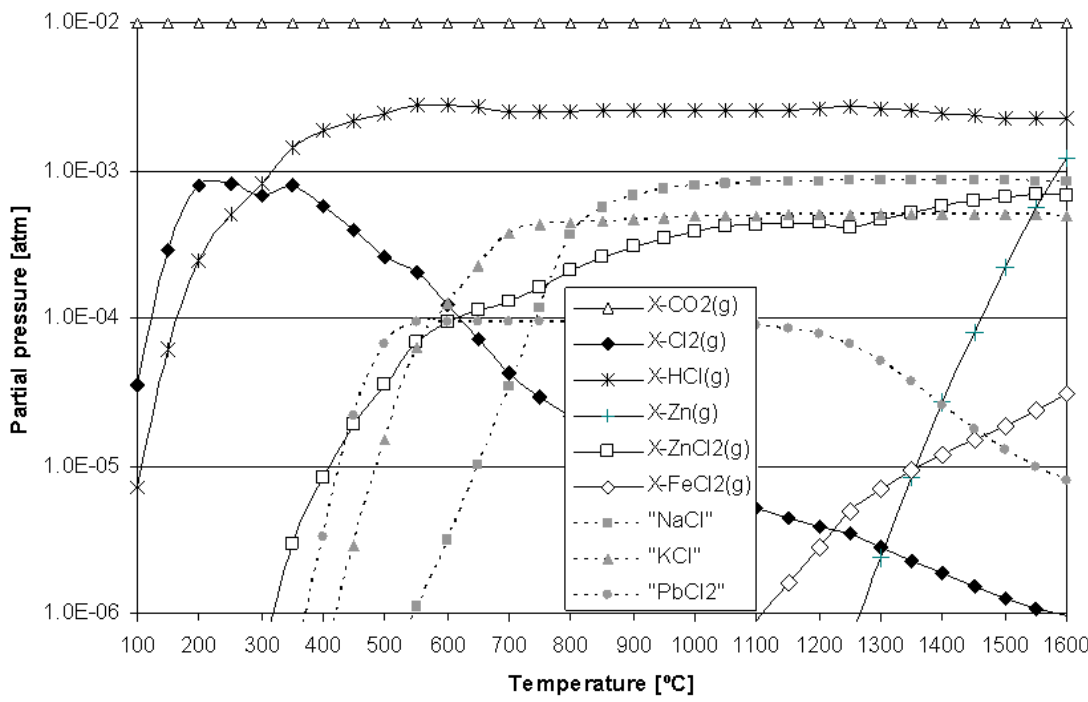

Figure 10. Gas phase constituents; system Fe-Zn-O-Cl-H-C-Na-K-Pb.

* Technical contribution to the 69th ABM International Annual Congress and to the ENEMET, July $21^{\text {st }}-25^{\text {th }}, 2014$, São Paulo, SP, Brazil. 


\subsection{Analysis of the Gas Phase}

The partial pressure of the gas phase constituents at equilibrium were determined and the values for some minor components are presented as a function of the temperature in Figures 8, 9 and 10.

Analysis of the minor constituents in the gas phase shows that the chlorides of zinc and iron, and gaseous $\mathrm{Zn}$ coexist at higher temperatures. Along with them, with the highest molar fraction is $\mathrm{HCl}$. With the cooling of the gas phase, the chlorides disappear, but not $\mathrm{HCl}$, which only shows the same trend of decline when the temperature is reduced to below $300-400{ }^{\circ} \mathrm{C}$. With an opposing trend, chlorine gas gradually increases its share, to the extent that the temperature decreases. The tendency (suddenly) reverses at $\sim 250{ }^{\circ} \mathrm{C}$. To find a reasonable explanation for this phenomenon, one must analyze the amount of chloride condensed phases, especially the zinc chloride.

Chlorides of $\mathrm{K}, \mathrm{Na}$ and $\mathrm{Pb}$ do exist in the gas phase, but lose importance as the temperature decreases.

\section{CONCLUSIONS}

The thermodynamic simulation on EAFD genesis using the Fe-O-Zn-Cl-H-C-Na-K-Pb system, considering the limited temperature range and the fixed input mass composition, showed that primarily iron oxides - mostly hematite and spinel (of iron and zinc - are generated), according to the proportion of components $\mathrm{Fe}$ and $\mathrm{Zn}$ in the charge.

Concerning chlorine, the lone condensed phase containing it appears at the end of the cooling process, below $250^{\circ} \mathrm{C}$, for the system containing $\mathrm{Cl}-\mathrm{H}-\mathrm{C}$ is $\mathrm{ZnCl}_{2}$. Later, with an increase in system complexity, other chloride-containing species also condense.

Element chlorine, in the intermediate and higher zone of temperatures, concentrates in the gas phase, especially in the chemical gaseous species $\mathrm{HCl}, \mathrm{Cl}_{2}$ and $\mathrm{ZnCl}_{2}$. This information is very interesting for those concerned with the corrosion in the steel parts of the exhaust system.

Worthy of note, the presence of lead in the gas phase is limited to the higher temperatures.

If there would be enough energy in the system to overcome the activation energy barrier that would trigger these transformations at the lower end of the temperature scale remains a non-answered question. Nevertheless, the computational thermodynamic tool is capable to set the trend that will be followed in the case of a negative as well in a positive answer.

\section{REFERENCES}

1 Guézennec AG, Huber JC, Patisson F, Sessiecq P, Birat JP, Ablitzer D. Dust formation in electric arc furnace: birth of the particles. Powder Technology. 2005;157:2-11.

2 Nyirenda RL. The processing of steelmaking flue dust: a review. Minerals Engineering. 1991;4(7-11):1003-25.

3 Nakayama M. New EAF dust treatment process - ESRF. 2012 [access in July 2013]. Available at: http://www.steelplantech.co.jp/wp-content/uploads/2012/08/ 201108_EAF_ Dust Treatment_fortlightMetalRecovery.pdf.

4 Dutrizac JE, Chen TT. The role of hydrometallurgy in the recycling of zinc, copper and lead. Acta Metallurgica Slovaca. 1998;(1):5-28.

* Technical contribution to the 69th $A B M$ International Annual Congress and to the ENEMET, July $21^{\text {st }}-25^{\text {th }}$, 2014, São Paulo, SP, Brazil. 
5 Birat JP, Arion A, Faral M, Baronnet F, Marquaire PM, Rambaut P. Abatement of organic emissions in EAF exhaust flue gas. La Revue de Métallurgie-CIT. 2001;98(10):839-854.

6 Nakayama M, Kubo H. Progress of emission control system in electric arc furnace meltshops. NKK Technical Review. 2001;jul.(84):16-23.

7 Memoli F, Ferri MB, Freitas JV. Aumento das plantas Consteel no mundo: flexibilidade para a carga contínua de gusa líquido e sucata no forno elétrico a arco agora na siderurgia brasileira. Tecnol. Metal. Mater. Miner. 2009;6(1):54-60.

8 Miranda R, Pakdel C, Roy C, Vasile C. Vacuum pyrolysis of commingled plastics containing PVC. Polymer Degradation and Stability. 2001;73(1):47-67.

9 Buzin PJWK, Vilela ACF, Heck NC. Thermodynamic analysis of EAFD generation aiming at the recycling: system Fe-O-Zn. In: Proceedings of the $67^{\text {th }}$ ABM Annual Congress; 31 July - 3 August 2012; Rio de Janeiro, Brazil. São Paulo: ABM; 2012.

10 Buzin PJWK, Vilela ACF, Heck NC. Thermodynamic analysis of EAFD generation using the Fe-O-Zn system. In: Proceedings of the $68^{\text {th }}$ ABM Annual Congress; 30 July - 2 August 2013; Belo Horizonte, Brazil. São Paulo: ABM; 2013.

11 Bale CW, Chartrand P, Degterov SA, Eriksson G, Hack K, Ben Mahfoud R, Melançon J, Pelton AD, Petersen S. FactSage thermochemical software and databases. Calphad. 2002;26(2):89-228. 